\title{
Åpen kirurgi og endovaskulær behandling av carotisstenose
}

\author{
Sammendrag \\ Bakgrunn. Pasienter med carotis- \\ stenose har høy risiko for slag tidlig \\ etter et transitorisk iskemisk anfall \\ og bør tilbys vurdering for profylaktisk \\ kirurgi innen to uker etter hendelsen. \\ Vi presenterer her Rikshospitalets \\ resultater for behandling av carotis- \\ stenose i perioden 2001-08.
}

\begin{abstract}
Materiale og metode. Materialet omfatter alle pasienter som ble behandlet for carotisstenose med enten trombendarterektomi eller endovaskulær stentbehandling i perioden 2001-08. Behandlingsprosedyrene registreres fortløpende i en virksomhetsdatabase. Nevrolog undersøker pasientene preoperativt og én og 12 måneder postoperativt.
\end{abstract}

Resultater. I observasjonsperioden ble 408 carotisstenoser behandlet. Median alder var 68 år (spredning 21-85 år), og 125 pasienter (31\%) var kvinner. 321 ble behandlet med trombendarterektomi. Av disse var 206 (64\%) symptomatiske stenoser. 87 ble behandlet endovaskulært, hvorav 53 (61\%) var symptomatiske. Forekomst av alvorlige slag og/eller død innen 30 dager etter trombendarterektomi var $1,9 \%$ ved symptomatiske og 1,1\% ved asymptomatiske stenoser, og etter endovaskulær behandling hhv. 1,9\% og 3,8\%.

Fortolkning. Vi har tilbudt stentbehandling til pasienter der kirurgi er komplisert (restenoser, stråleinduserte stenoser o.a.). Resultater kan derfor ikke sammenliknes i vårt materiale. Slagforebyggende effekt av trombendarterektomi er dokumentert, og det er kjent at komplikasjonsrisikoen er høyere ved stentbehandling enn ved kirurgi. Helsehjelp ved carotisstenoser bør inkluderes i planlagte nasjonale retningslinjer for behandling av hjerneslag.

\section{Kirsten Krohg-Sørensen}

kirsten.krohg-sorensen@rikshospitalet.no

Karkirurgisk seksjon

Thoraxkirurgisk avdeling

Per Snorre Lingaas

Thoraxkirurgisk avdeling

Søren Jacob Bakke

Nevroradiologisk seksjon

Bilde- og intervensjonsklinikken

Mona Skjelland

Nevrologisk avdeling

Oslo universitetssykehus, Rikshospitalet 0027 Oslo

Hjerneslag er den vanligste årsaken til invaliditet og den tredje vanligste dødsårsaken $i$ Norge. Insidensen øker med økende alder. $80 \%$ er iskemiske slag, og $25-30 \%$ av disse skyldes aterosklerose i precerebrale arterier $(1,2)$. Hver fjerde slagpasient har hatt transitorisk iskemisk anfall (TIA) som forvarsel, og ca. $40 \%$ av disse skjedde de siste sju dager før slaget (3). Risiko for slag etter TIA er spesielt høy dersom etiologien er plakkembolier fra en signifikant stenose i arteria carotis (4). Slagforebyggende effekt av carotistrombendarterektomi er dokumentert i flere store randomiserte studier (5-11). Det er også dokumentert at risikoreduksjonen som oppnås ved kirurgi er betydelig de første uker etter TIA og deretter avtakende $(12,13)$. Randomiserte studier der man sammenlikner kirurgi og endovaskulær behandling har konkludert med at kirurgi gir bedre resulater (14-18).

Vi presenterer her Rikshospitalets praksis og resultater ved kirurgisk og endovaskulær behandling av carotisstenose og diskuterer hvordan helsetilbudet til disse pasientene kan organiseres.

\section{Materiale og metode}

Alle inngrep for carotisstenose ved vårt sykehus registreres prospektivt $i$ en virksomhetsdatabase. Pasientene undersøkes klinisk av nevrolog samt med tripleks ultralyd av halskar, CT-angiografi av arcus, halskar og intrakraniale kar, og MR cerebri. Nevrologundersøkelse inkludert tripleksundersøkelse av halskar gjentas dagen før operasjonen samt én og 12 måneder postoperativt. Ventetid fra symptomdebut til behandling og fra mottatt henvisning til behandling er registrert bare i 2008 .

16 pasienter er randomisert til stentbehandling eller kirurgisk behandling som ledd $\mathrm{i}$ en internasjonal multisenterstudie
(ICSS) (18). Ellers er stentbehandling kun benyttet hos pasienter der kirurgi var kontraindisert pga. restenoser, tidligere kirurgi på halsen, stråleinduserte stenoser, langstrakte, distale stenoser, vaskulitt og fibromuskulær dysplasi. Postoperative hjerneslag defineres som nevrologiske utfall som varer mer enn 24 timer. Hvis symptomene vedvarer ved ettårskontroll defineres slaget som alvorlig, uavhengig av invaliditetsgrad. Livslang behandling med acetylsalisylsyre og statin anbefales.

\section{Kirurgi}

Trombendarterektomi gjøres i generell anestesi. Platehemmerbehandling kontinueres uten avbrudd, men kombinasjon av acetylsalisylsyre og klopidogrel er ikke innført som rutine. Det gis i tillegg 5000 IE heparin peroperativt. Vi bruker rutinemessig shunt fra a. carotis communis til distale a. carotis interna (fig 1a), og hjernen monitoreres med INVOS Cerebral Oximeter (Somanetics Corporation), eller transkranial doppler med hastighetsmåling i arteria cerebri media og embolideteksjon. Det gjøres endarterektomi via langsgående arteriotomi (fig 1a). Distale intimakant festes med suturer før arteriotomien lukkes direkte med fortløpende 7-0 Prolene (fig 1b). Dersom karet har lite kaliber, brukes en polyesterlapp (Hemashield Finesse (Boston Scientific Corp)) (fig 1c).

Pasientene vekkes på operasjonsstuen og kontaktbarhet og bevegelse i ekstremiteter vurderes. Monitorering av blodtrykk (intraarterielt) og puls kontinueres til neste morgen.

\section{Endovaskulær behandling}

Behandling utføres av nevroradiologer. Pasienten er våken, men sederes etter behov. Acetylsalisylsyre og klopidogrel startes mi-

\section{Hovedbudskap}

- Kirurgisk behandling av carotisstenoser forebygger hjerneslag

- Stentbehandling har høyere komplikasjonsrisiko enn kirurgi og bør kun brukes når kirurgi er spesielt komplisert

- Risiko for hjerneslag er høy tidlig etter et transitorisk iskemisk anfall, og kirurgi bør derfor tilbys innen to uker

- Kirurgisk og endovaskulær behandling av carotisstenoser bør sentraliseres til et regionalt slagsenter 

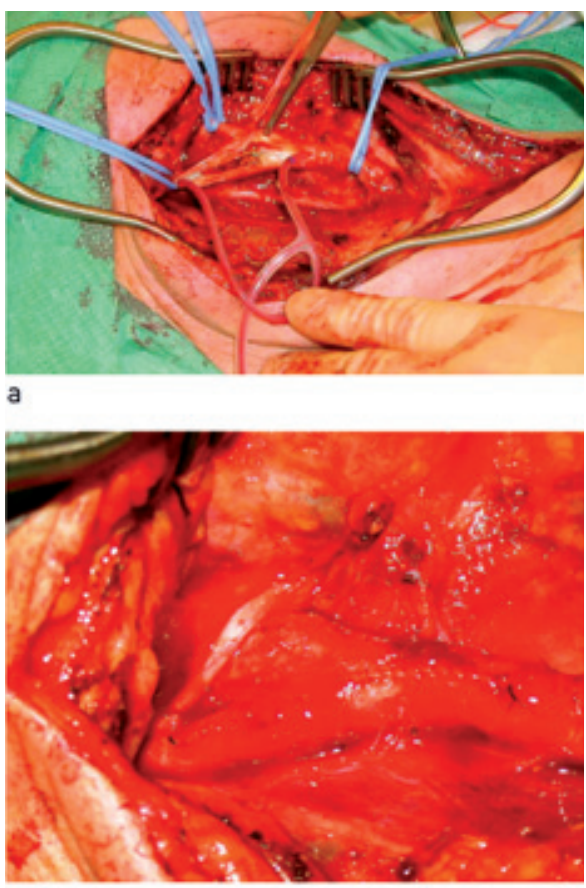

b

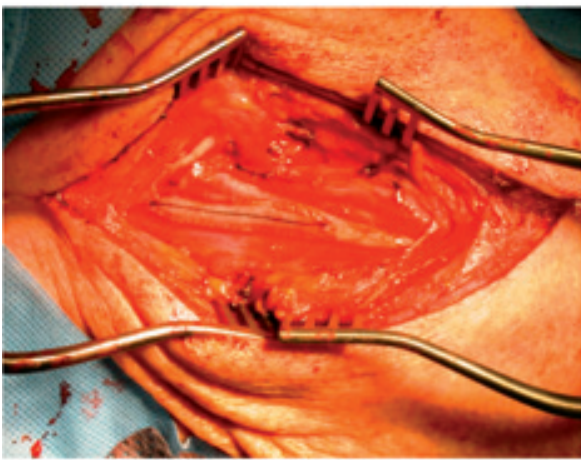

Figur 1 Trombendarterektomiavarteria carotis. Pruitt-Inahara shunt fra a. carotis communis til a carotis interna. a) Arterien er klippet opp gjennom plakket. b) Arteriotomien er lukket med direkte sutur eller cl med lapp

nimum fire dager før prosedyren og kontinueres i ett år etter inngrepet. Det gis heparin under prosedyren. Blodtrykket monitoreres og styres som ved kirurgi. Det er beredskap for behandling av arytmier som kan forekomme ved ballongdilatasjon i carotisbifurkaturen. Tilgang er vanligvis fra høyre arteria femoralis, og det benyttes spesielle føringskatetre og selvekspanderende stenter (fig 2). Før stenten føres opp og dilateres, plasseres en beskyttende filterståltråd distalt i a. carotis for å samle opp mikropartikler som løsner under prosedyren. Deretter snøres filteret sammen og fjernes via føringskateteret. Et lite antall pasienter ble behandlet kun med ballongdilatasjon uten stent.

Studien er godkjent av personvernombudet ved Oslo universitetssykehus, Rikshospitalet.

\section{Resultater}

I observasjonsperioden har vi behandlet 408 carotisstenoser, 321 med endarterektomi og
87 endovaskulært, hvorav sju bare med ballongdilatasjon uten stent. 125 pasienter $(30,6 \%)$ var kvinner, og median alder var 68 år (spredning 21-85 år). 259 av pasientene $(63,5 \%)$ hadde cerebrovaskulære symptomer fra ipsilaterale hemisfære i løpet av siste 180 dager før inngrepet, $36(8,8 \%)$ hadde globale hypoperfusjonssymptomer eller cerebrovaskulære symptomer fra kontralaterale hemisfære med okkludert kontralateral carotis, og $113(27,7 \%)$ var uten cerebrovaskulære symptomer.

Pasientene hadde betydelig komorbiditet, og 101 (24,8\%) gjennomgikk også planlagt hjertekirurgi/perkutan koronar intervensjon (PCI) før, samtidig med eller etter behandling for carotisstenose (tab 1).

Innen 30 dager etter trombendarterektomi fikk 11 pasienter $(3,4 \%)$ hjerneslag, hvorav to døde. Fem slag var alvorlige. Fire pasienter hadde ingen sekvele etter ett år. Av ti iskemiske slag var seks ipsilaterale (ett dødelig) og fire kontralaterale til operert a. carotis. En hjerneblødning (ipsilateral) var dødelig. Etter endovaskulær behandling fikk fem pasienter $(5,7 \%)$ slag innen 30 dager etter inngrepet. Alle var iskemiske slag, fire var ipsilaterale og ingen av pasientene døde. To slag var alvorlige. Tre pasienter var symptomfrie etter ett år. Ett av de to alvorlige slagene oppsto hos en pasient som fikk en disseksjon $\mathrm{i}$ a. carotis og aortaveggen under prosedyren. Forekomst av postoperative alvorlige slag relatert til preoperative symptomer vises i tabell 2.

Fem pasienter fikk hjernenerveskade etter trombendarterektomi, tre av nervus hypoglossus, hvorav én forbigående, og to av nervus vagus, begge forbigående. Etter trombendarterektomi ble åtte pasienter reoperert for blødning. Etter endovaskulær behandling fikk fire pasienter blødning i lysken. To ble operert og to behandlet med ultralydveiledet kompresjon.

Tid fra symptomdebut til behandling var i 2008 mediant 33 dager (spredning 1-137 dager). Tid fra mottatt henvisning til behandling var mediant 14 dager (spredning 0-90 dager).

\section{Diskusjon}

Aktiv forebyggende behandling, akutt behandling av slag med trombolytisk behandling og eventuelt endovaskulær behandling på intrakraniale kar samt riktig rehabilitering kan redusere komplikasjoner av hjerneslag. Behandling i slagenheter anbefales (19), inndelt i primære og regionale enheter med forpliktende samarbeid (20). Det er laget retningslinjer i flere land, og også i Norge utarbeides nasjonale retningslinjer for behandling av hjerneslag i regi av Helsedirektoratet. Primær og sekundær forebyggende behandling dreier seg om endringer i livsstil (kosthold, fedme, røyking), medikamentell behandling med platehemmer og statiner, optimal behandling av diabetes, hypertensjon, hjertesykdom og atrieflimmer
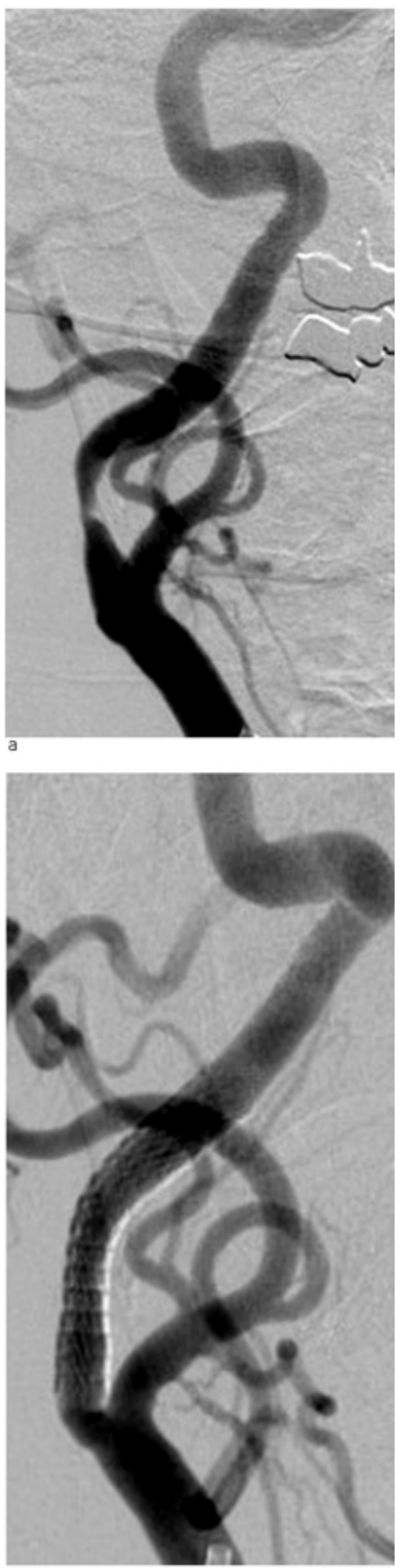

b

Figur 2 Endovaskulær behandling av arteria carotis. a) Angiografisk fremstilling av stenose. b) Etter implantasjon av stent 
Tabell 1 Preoperative risikofaktorer for pasienter behandlet for carotisstenose med trombendarterektomi eller endovaskulær behandling ved Rikshospitalet 2001-08. Antall (\%) hvis ikke annet er oppgitt

\begin{tabular}{|c|c|c|c|}
\hline & $\begin{array}{l}\text { Trombendarter- } \\
\text { ektomi } \\
(\mathrm{n}=321)\end{array}$ & $\begin{array}{l}\text { Endovaskulær be- } \\
\text { handling } \\
\text { (n }=87)\end{array}$ & $\begin{array}{c}\text { Alle } \\
(N=408)\end{array}$ \\
\hline Alder, median (spredning) & $68(37-85)$ & $69(21-83)$ & $68(21-85)$ \\
\hline Andel kvinner & $94(29,3)$ & $31(35,6)$ & $125(30,6)$ \\
\hline Hjertesykdom & $245(76,3)$ & 60 (69) & $305(74,8)$ \\
\hline $\begin{array}{l}\text { Planlagt hjertekirurgi/PCI før, samtidig } \\
\text { med eller etter behandling for carotis- } \\
\text { stenose }\end{array}$ & $89(27,8)$ & $12(13,8)$ & $101(24,8)$ \\
\hline Blodtrykksbehandling & $233(72,6)$ & $59(67,8)$ & $292(71,6)$ \\
\hline Kronisk obstruktiv lungesykdom & $39(12,1)$ & $17(19,5)$ & $56(13,7)$ \\
\hline $\begin{array}{l}\text { Stenose eller okklusjon av kontra- } \\
\text { lateral carotis }\end{array}$ & $150(46,7)$ & $44(50,6)$ & $194(47,5)$ \\
\hline Behandling for restenose & 1 & $31(35,6)$ & $32(7,8)$ \\
\hline Behandling for stråleindusert stenose & 0 & $8(9,2)$ & $8(2,0)$ \\
\hline
\end{tabular}

Tabell 2 Forekomst av slag med vedvarende symptomer mer enn ett år postoperativt eller død innen 30 dager etter inngrepet for pasienter med symptomatisk stenose, multiple stenoser eller asymptomatiske stenoser

\begin{tabular}{|c|c|c|c|c|}
\hline & \multicolumn{2}{|c|}{$\begin{array}{l}\text { Trombendarterektomi } \\
\qquad(\mathrm{n}=321)\end{array}$} & \multicolumn{2}{|c|}{$\begin{array}{l}\text { Endovaskulær behandling } \\
\qquad(\mathrm{n}=87)\end{array}$} \\
\hline & Antall (\%) & $\begin{array}{l}\text { Alvorlige slag } \\
\text { eller død innen } \\
30 \text { dager }\end{array}$ & Antall (\%) & $\begin{array}{l}\text { Alvorlige slag } \\
\text { eller død innen } \\
30 \text { dager }\end{array}$ \\
\hline $\begin{array}{l}\text { Symptomatisk stenose } \\
\text { (symptom fra ipsilateral } \\
\text { hemisfære) }\end{array}$ & $206(64,2)$ & $4(1,9)$ & $53(60,9)$ & $1(1,9)$ \\
\hline $\begin{array}{l}\text { Multiple halskarstenoser } \\
\text { med globale symptomer eller } \\
\text { symptomer fra kontralateral } \\
\text { hemisfære }\end{array}$ & $28(8,7)$ & $2(7,1)$ & $8(9,2)$ & 0 \\
\hline Asymptomatiske stenoser & $87(27,1)$ & $1(1,1)$ & $26(29,9)$ & $1(3,8)$ \\
\hline
\end{tabular}

samt intervensjoner som carotiskirurgi, ablasjonsbehandling av atrieflimmer og hjertekirurgi.

Siden risiko for slag er svært høy de første dager/uker etter TIA, er det viktig å ha rutiner for hvordan og hvor raskt pasienter med symptomer på TIA/slag skal henvises, undersøkes og behandles. I Storbritannia anbefales at pasienter med TIA skal vurderes av spesialist innen 24 timer. Slagpasienter skal henvises til akutte slagenheter. Dersom intervensjon på a. carotis er aktuelt, skal bildediagnostikk være gjort innen én uke og kirurgisk behandling innen to uker (21). Rask henvisning til spesielle TIA/slagenheter reduserer risiko for invalidiserende slag $(22,23)$.

Etter at det $\mathrm{i}$ de senere år er vist at man forhindrer flere hjerneslag ved å operere tidlig etter symptomdebut $(4,12,13)$, har disse pasientene hos oss vært vurdert som hastepasienter. Pasientene henvises via nevrologiske avdelinger eller slagenheter, men det går fremdeles for lang tid fra symptomdebut til behandling. Vi trenger bedre rutiner for samarbeid rundt hvilke undersøkelser som skal gjøres og hvor og hvordan de skal utføres. CT-angiografi bør gjøres etter en standardisert protokoll. Rådatabilder kan overføres teleradiologisk mellom sykehus. De nasjonale retningslinjer for hjerneslagbehandling som er under utarbeiding, må sikre at pasienter med cerebrovaskulære symptomer undersøkes i kompetente multidisiplinære fagmiljøer. Det bør etableres behandlingskjeder og forpliktende nettverk mellom sykehus som sikrer at kirurgi kan tilbys innen to uker hos pasienter med carotisstenose som årsak til symptomene.

Foruten tidsaspektet er slagforebyggende effekt av carotiskirurgi avhengig av at inngrepet kan utføres med lav perioperativ morbiditet og mortalitet. Den risikoreduksjonen for slag som oppnås ved kirurgi sammenliknet med sykdommens naturlige forløp, påvirkes direkte av økt forekomst av kirurgiske komplikasjoner. For carotiskirurgi er derfor kvalitetskravet en del av indikasjonsstillingen; det kreves at kirurgi for symptomatiske stenoser skal gjøres med lavere enn $6 \%$ risiko for død eller slag innen 30 dager etter inngrepet (9). På grunn av dette bør alle avdelinger som behandler carotisstenoser, publisere sine perioperative komplikasjonsrater. Våre resultater er innenfor anbefalte grenser. Dette kravet er basert på resultater i randomiserte studier (5-9), der symptomatisk stenose ble definert som ipsilaterale symptomer $<180$ dager før randomisering. Det diskuteres om man må forvente - og godta - høyere komplikasjonsrisiko ved inngrep tidlig etter symptomer. Plakket er da ustabilt og vulnerabelt, med høyere embolirisiko. Det er holdepunkter for at operasjonsrisikoen øker ved tidlig kirurgi, spesielt etter hjerneslag (24). Pasienter med større hjerneinfarkt, og pasienter med ustabile eller økende kliniske symptomer (crescendo TIA) har høy operasjonsrisiko, men har også svært høy risiko for slag uten kirurgisk behandling. Svært få slike pasienter har vært inkludert i de randomiserte studiene, og spesifikk dokumentasjon for denne subgruppen er mangelfull (4). Det er imidlertid holdepunkter for at selv med noe høyere operasjonsrisiko tidlig etter hendelsen, vil man forhindre flere hjerneslag ved tidlig kirurgi enn ved utsettelse, fordi risiko for nye hendelser er så høy de første par ukene (13).

Det er også dokumentert statistisk signifikant risikoreduksjon for hjerneslag ved kirurgisk behandling av asymptomatiske carotisstenoser $(10,11)$, men tallmessig er effekten beskjeden, og for noen pasienter neppe klinisk relevant (25). Det har i Skandinavia og Nord-Europa vært en konservativ innstilling til kirurgisk behandling ved asymptomatiske stenoser, mens denne gruppen $\mathrm{i}$ USA har vært dominerende i operasjonsmaterialene. Andelen hos oss er ca. $30 \%$. Vi behandler en del pasienter med kombinert hjerte- og carotissykdom der carotiskirurgi gjøres som forberedelse for å redusere risiko for peroperative slag ved hjertekirurgi (26).

Indikasjon for carotiskirurgi avgjøres vesentlig på grunnlag av stenosegrad og symptomer. Ved asymptomatiske stenoser diskuteres hvordan man kan identifisere undergrupper som har mest nytte av intervensjon. Ved symptomatiske stenoser anbefales det å operere alle som har stenoser der reduksjon i diameter er over $50 \%$ sammenliknet med distale a. carotis interna (25). Det forskes på å finne mer presise metoder enn stenosegrad for å identifisere ustabile plakk med høy risiko for embolisering, både ved undersøkelse av selve plakket med ultralyd $(27,28)$ eller positronemisjonstomografi (PET)-CT (29), ved undersøkelse av hjernen med MR eller embolideteksjon med transkranial doppler (28), eller ved biokjemiske markører som kan måles i blodprøver (30-32). Når inngrep på asymptomatisk stenose vurderes, vil man i klinisk praksis legge vekt på ultralydbedømt plakkmorfologi, MR/CTfunn av iskemiske lesjoner i ipsilateral hjernehalvdel samt påviste embolier ved transkranial dopplerundersøkelse. Nytten av PET og biokjemiske markører er usikker, og mer dokumentasjon er nødvendig. 
Vi gjør carotisendarterektomi i generell anestesi. En nylig publisert randomisert studie sammenliknet lokal med generell anestesi og man fant at metodene er likeverdige med hensyn til risiko for slag, død og hjerteinfarkt innen 30 dager samt lengde på sykehusoppholdet og livskvalitet postoperativt (33).

Det er gjort flere randomiserte studier for sammenlikning av åpen kirurgi og stentbehandling, og flere metaanalyser er publisert (14-17). Ca. 3000 pasienter er inkludert totalt, og resultatene viser at stentbehandling gir noe høyere risiko for komplikasjoner enn kirurgi. Hos oss er gruppene ikke randomisert (med unntak av 16 pasienter inkludert i ICSS-studien), og vi kan derfor ikke sammenlikne behandlingsmetodene $\mathrm{i}$ vårt materiale. Vi har ikke tilbudt stentbehandling rutinemessig, men kun når kirurgi er kontraindisert på grunn av lokale forhold på halsen. 30 dagers resultater fra ICSS-studien er nylig publisert (18). Studien har inkludert 1713 pasienter og man konkluderer med at trombendarterektomi fortsatt er anbefalt behandling. Innen 30 dager etter behandling var det 8,5\% forekomst av slag eller død eller hjerteinfarkt etter stentbehandling, sammenliknet med $5,1 \%$ etter kirurgi $(\mathrm{p}=0,004)$. Ut fra dette vil vi fortsette vår praksis med å tilby stentbehandling kun når kirurgi er komplisert, med høy risiko for hjernenerveskader lokalt på halsen. Våre resultater indikerer at stentbehandling kan utføres med akseptable resultater hos disse pasientene.

Kvalitet på carotiskirurgi er volumavhengig (34-36). Det er vanskelig å avgjøre om det er kirurgvolum eller sykehusvolum som har mest betydning, og også hva som er terskelverdi for stabil kvalitet. I England er det anbefalt at avdelinger med et volum på under 35 inngrep per år bør henvise pasientene til andre (34). I Norge ble det i 2006 utført carotiskirurgi på minst 17 sykehus, og ni av disse gjorde færre enn 15 inngrep (37). En sentralisering av virksomheten til færre sykehus er ønskelig, slik det også anbefales i Sverige (38).

\section{Konklusjon}

Våre resultater både ved kirurgi og endovaskulær behandling er i tråd med internasjonale krav vedrørende risiko for postoperative slag og død, men ventetid fra symptom til behandling av symptomgivende carotisstenose er fremdeles for lang. Behandling av carotisstenoser bør sentraliseres mer enn dagens praksis og ses i sammenheng med regionale multidisiplinære slagenheter. Utredning og behandling av pasienter med carotisstenoser bør inkluderes i de nasjonale retningslinjene for hjerneslagbehandling som er under utarbeiding.

Oppgitte interessekonflikter: Ingen
Litteratur

1. Bettermann K, Toole J. Diagnostic evaluation and medical management of patients with ischemic cerebrovascular disease. I: Rutherford RB, red. Vascular surgery, 6. utg. Philadelphia, PA: Elsevier, 2005: 1897-916.

2. Ellekjær H, Selmer R. Hjerneslag - like mange rammes, men prognosen er bedre. Tidsskr Nor Lægeforen 2007: 127: 740-3.

3. Rothwell PM, Warlow CP. Timing of TIAs preceding stroke: time window for prevention is very short. Neurology 2005; 64: 817-20.

4. Rothwell PM. Prediction and prevention of stroke in patients with symptomatic carotid stenosis: The high-risk period and the high-risk patient. Eur J Vasc Endovasc Surg 2008; 35: 255-63.

5. European Carotid Surgery Trialists' Collaborative Group. MRC European Carotid Surgery Trial: Interim results for symptomatic patients with severe $(70-99 \%)$ or with mild $(0-29 \%)$ carotid stenosis. Lancet 1991; 337: 1235-43

6. North American Symptomatic Carotid Endarterectomy Trial Collaborators. Beneficial effect of carotid endarterectomy in symptomatic patients with high-grade carotid stenosis. N Engl J Med 1991; 325: 445-53.

7. European Carotid Surgery Trialists' Collaborative Group. Randomised trial of endarterectomy for recently symptomatic carotid stenosis: final results of the MRC European Carotid Surgery Trial (ECST). Lancet 1998; 351: 1379-87.

8. Barnett HJ, Taylor DW, Eliasziw M et al. The North American Symptomatic Carotid Endarterectomy Trial Collaborators. Benefit of carotid endarterectomy in patients with symptomatic moderate or severe stenosis. N Engl J Med 1998; 339: 1415-25.

9. Cina C, Clase C, Haynes RB. Carotid endarterectomy for symptomatic carotid stenosis. Cochrane Database Syst Rev 1999; nr.3: CD001081. DOI: 10.1002/14651858.CD001081. www.mrw. interscience.wiley.com/cochrane/clsysrev/ articles/CD001081/frame html (24.9.2009).

10. Executive Committee for the Asymptomatic Carotid Atherosclerosis Study. Endarterectomy for asymptomatic carotid artery stenosis. JAMA 1995; 273: $1421-8$.

11. MRC Asymptomatic Carotid Surgery Trial (ACST) Collaborative Group. Prevention of disabling and fatal strokes by successful carotid endarterectomy in patients without recent neurological symptoms: randomised controlled trial. Lancet 2004; 363: $1491-502$.

12. Rothwell PM, Eliasziw M, Gutnikov SA et al. Carotid Endarterectomy Trialists Collaboration. Endar terectomy for symptomatic carotid stenosis in relation to clinical subgroups and timing of surgery. Lancet 2004; 363: 915-24.

13. Naylor AR. Regarding «Early carotid endarterec tomy in symptomatic patients is associated with poorer perioperative outcomes.» J Vasc Surg 2007. 46: 616-7.

14. Luebke T, Aleksic M, Brunkwall J. Meta-analysis of randomized trials comparing carotid endarterectomy and endovascular treatment. Eur J Vasc Endovasc Surg 2007: 34: 470-9.

15. Brahmanandam S, Ding EL, Conte MS et al. Clinical results of carotid artery stenting compared with carotid endarterectomy. J Vasc Surg 2008; 47 $343-9$

16. Murad MH, Flynn DN, Elamin MB et al. Endtarterectomy versus stenting for carotid artery stenosis: a systematic review and meta-analysis. J Vasc Surg 2008; 48: 487-93.

17. Ringleb PA, Chatellier G. Hacke W et al Safety of endovascular treatment of carotid artery stenosis compared with surgical treatment: A meta-analysis. J Vasc Surg 2008; 47: 350-5.

18. The International Carotid Stenting Study (ICSS) Website. www cavatas.com (24.9.2009).

19. Indredavik B. Stroke unit care is beneficial both for the patient and for the health service and should be widely implemented. Stroke 2009; 40: 1-2

20. Frich JC. Slagkraftig ledelse. Tidsskr Nor Legeforen 2008; 128: 679

21. National Collaborating Centre for Chronic Conditions. Stroke: national clinical guidelines for diagnosis and clinical management of acute stroke and transient ischemic attack (TIA). London: Royal College of Physicians, 2008. www.rcplondon.ac.uk (24.9.2009).
22. Rothwell PM, Giles MF, Chandratheva A et al. Early use of Existing Preventive Strategies for Stroke (EXPRESS) study. Effect of urgent treatment of transient ischemic attack and minor stroke on early recurrent stroke (EXPRESS Study): a prospective population-based sequential comparison. Lancet 2007; 370: 1432-42.

23. Lavallée PC, Meseguer E, Abboud H et al. A transient ischemic attack clinic with round-the-clock access (SOS-TIA): feasibility and effects. Lancet Neurol 2007; 6: 953-60.

24. Rockman CB, Maldonado TS, Jacobowitz GR et al. Early carotid endarterectomy in symptomatic patients is associated with poorer perioperative outcomes. J Vasc Surg 2006; 44: 480-7.

25. Krohg-Sørensen K, Bakke SJ, Russell D. Operativ og endovaskulær behandling av carotisstenose når er det aktuelt? Tidsskr Nor Lægeforen 2007; 127: 903-7.

26. Krohg-Sørensen K, Lingaas PS, Solberg S et al. Behandling av kombinert carotisstenose og hjertesykdom. Tidsskr Nor Lægeforen 2005; 125: 2017-20.

27. Mathiesen EB. Risiko for hjerneslag ved carotisstenose - hvilken betydning har plakkmorfologi? Tidsskr Nor Lægeforen 2003; 123: 782-4.

28. Skjelland M, Krohg-Sørensen K, Tennøe B et al. Cerebral microemboli and brain injury during carotid artery endarterectomy and stenting. Stroke 2009; 40: $230-4$.

29. Wallis de Vries BM, van Dam GM, Tio RA et al. Current imaging modalities to visualize vulnerability within the atherosclerotic carotid plaque. J Vasc Surg 2008; 48: 1620-9.

30. Handberg A, Skjelland M, Michelsen AE et al. Soluble CD36 in plasma is increased in patients with symptomatic atherosclerotic carotid plaques and is related to plaque instability. Stroke 2008; 39: $3092-5$

31. Skjelland M, Michelsen AE, Krohg-Sørensen K et al. Plasma levels of granzyme $B$ are increased in patients with lipid-rich carotid plaques as determined by echogenicity. Atherosclerosis. 2007; 195 e142-6.

32. Lofthus I, Thompson M. Plaque biology: Interesting science or pharmacological treasure trove? Eur J Vasc Endovasc Surg 2008; 36: 507-16.

33. GALA Trial Collaborative Group. General anaesthesia versus local anaesthesia for carotid surgery (GALA): a multicentre, randomised controlled trial. Lancet 2008: 372: 2132-42.

34. Holt PJ, Poloniecki JD, Loftus IM et al. The relationship between hospital case volume and outcome from carotid endarterectomy in England from 2000 to 2005. Eur J Vasc Endovasc Surg 2007; 34: $646-54$

35. Holt PJ, Poloniecki JD, Loftus IM et al. Meta-analysis and systematic review of the relationship between hospital volume and outcome following carotid endarterectomy. Eur J Vasc Endovasc Surg 2007: 33: 645-51.

36. Nazarian SM, Yenokan G, Griswold ME et al. Statistical modelling of the volume-outcome effect for carotid endarterectomy for 10 years of a statewide database. J Vasc Surg 2008; 48: 343-50.

37. Norsk karkirurgisk forening. Rapporter fra NORKAR 2006. www.legeforeningen.no/ index.gan?id=133122\&subid=0 (24.9.2009).

38. Gottsäter A, Mätzsch T. Kirurgi snart även primärprevention vid slaganfall av höggradig karotisstenos. Läkartidningen 2004; 101: 1821-7.

Manuskriptet ble mottatt 29.1. 2009 og godkjent 24.9. 2009. Medisinsk redaktør Michael Bretthauer. 